Чёрная Татьяна Владимировна, доктор философии в области психологии, профессор МКА, руководитель регионального отделения Европейской Академии естественных наук, психолог Инклюзивно-ресурсного центра №3 Деснянского района г. Киева, 02156, ул. Братиславская 14-а, г. Киев, Украина;

ORCID ID 0000-0002-2396-4377

\title{
ФОРМИРОВАНИЕ ДВИГАТЕЛЬНЫХ НАВЫКОВ У ДЕТЕЙ С АУТИЗМОМ ПРИ ПОМОЩИ КОМПЛЕКСНОЙ ИГРОВОЙ КИНЕЗИТЕРАПИИ
}

\begin{abstract}
Анотація
Чорна Т. В., доктор філософії в галузі психології, професор МКА, керівник регіонального відділення Європейської Академії природничих наук, психолог інклюзивної-ресурсного центру №3 Деснянського району м. Києва; м. Київ, Україна. Формування рухових навичок у дітей з аутизмом за допомогою комплексної ігрової кінезітерапії.

Ключові слова: діти, рухові навички, кінезітерапія, аутизм, сенсорна інтеграція.

Постановка проблеми. Згідно зі статистичними даними, кількість дітей 3 аутизмом з кожним роком збільшується в усьому світі, при цьому у третини аутичних дітей $є$ рухові порушення. Рухові проблеми зустрічаються так само часто, як і когнітивні порушення. Тому фізичні навантаження необхідні в комплексній програмі занять для дитини з аутизмом. Фізкультура може стати підтримкою і провідником в соціум для багатьох дітей, каталізатором в правильній побудові корекційно-розвиваючому процесі для дитини з аутизмом.
\end{abstract}


Аналіз останніх досліджень і публікацій. Сьогодні діти 3 аутизмом стали невід'ємною частиною сучасного суспільства. Захворюваність на аутизм в Києві за останні вісім років зросла в 4,5 рази. Незважаючи на велику кількість досліджень і публікацій, проблема раннього дитячого аутизму є актуальною в області практичної медицини, психології, корекційної педагогіки.

Діти з аутизмом не тільки відрізняються своєю поведінкою, мисленням, сприйняттям світу. У них також часто зустрічаються рухові порушення у вигляді незграбності, незвичайної ходи, координації руху, гипотонус або гіпертонус м'язів. У дітей рухові розлади обмежують можливості для розвитку і пізнання світу. Це призводить до замкнутості, обмежує соціальну взаємодію. Тому фізкультура може стати підтримкою і провідником в соціум для багатьох дітей, каталізатором в правильній побудові корекційно-розвиваючого процесу для дитини з аутизмом.

Формулювання мети статті. Мета дослідження - вивчити рухові особливості дітей 3 аутизмом та розробити авторський ефективний метод формування у них рухових навичок.

Виклад основного матеріалу. Метод комплексної ігрової кінезітерапії, розроблений нами під керівництвом професора А. П. Чуприкова, спрямований на корекцію психологічних особливостей та сенсорики дітей 3 аутизмом i відхиленнями у розвитку психіки та поведінки. За допомогою цього методу, з'являється можливість впливати на онтогенез психіки на самому ранньому етапі, коли дитина ще не може вступати в мовний контакт. Комплексність методу полягає в залученні різних прийомів впливу на органи чуття і кістковом'язову систему (пальцевий масаж, елементи краніо-сакральної терапії, елементи йоги, динамічна гімнастика на м'ячі для фітнесу, сенсорні ігри). Важливим компонентом ігрової кінезітерапії є заняття на м'ячі. 
Для батьків це також є хорошою терапією, тому що вони із задоволенням спостерігають за заняттям, вчаться новим прийомам у грі з дитиною, завдяки чому дитина стає більш радісною, розкривається в більшому обсязі.

Висновки i перспективи подальших досліджень. Метод ігрової кінезітерапії з використанням м'яча для фітнесу можна рекомендувати для формування психомоторної та інтелектуальної діяльності дитини і становлення у нього найважливіших рухових навичок, що складають основу не тільки ігровий, але також навчальної та трудової діяльності. Цей універсальний метод оздоровлення дитини 3 аутизмом може застосовуватися як самостійно, так і в поєднанні з іншими медичними і психолого-педагогічними методами корекції

\section{Аннотация}

Чёрная Т. В., доктор философии в области психологии, профессор МКА, руководитель регионального отделения Европейской Академии естественных наук, психолог Инклюзивно-ресурсного центра №3 Деснянского района г. Киева; г. Киев, Украина. Формирование двигательных навыков у детей с аутизмом при помощи комплексной игровой кинезитерапии.

Ключевые слова: дети, двигательные навыки, кинезитерапия, аутизм, сенсорная интеграция.

Постановка проблемы. Согласно статистическим данным, количество детей с аутизмом с каждым годом увеличивается во всем мире, при этом у трети аутичных детей есть двигательные нарушения. Двигательные проблемы встречаются так же часто, как и когнитивные нарушения. Поэтому физические нагрузки необходимы в комплексной программе занятий для ребенка с аутизмом. Физкультура может стать поддержкой и проводником в социум для многих детей, катализатором в правильном построении коррекционноразвивающем процессе для ребенка с аутизмом. 
Анализ последних исследований и публикаций. Сегодня дети с аутизмом стали неотъемлемой частью современного общества. Заболеваемость аутизмом в Киеве за последние восемь лет выросла в 4,5 раза. Несмотря на большое количество исследований и публикаций, проблема раннего детского аутизма является актуальной в области практической медицины, психологии, коррекционной педагогики.

Дети с аутизмом не только отличаются своим поведением, мышлением, восприятием мира. У них еще часто встречаются двигательные нарушения в виде неуклюжести, необычной походки, координации движения, гипотонус или гипертонус мышц. У детей двигательные расстройства ограничивают возможности для развития и познания мира. Это приводит к замкнутости, ограничивает социальное взаимодействие. Поэтому физкультура может стать поддержкой и проводником в социум для многих детей, катализатором в правильном построении коррекционно-развивающего процесса для ребенка с аутизмом.

Формулирование цели статьи. Цель исследования - изучить двигательные особенности детей с аутизмом и разработать авторский эффективный метод формирования двигательных навыков у детей с аутизмом.

Изложение основного материала. Метод комплексной игровой кинезитерапии, разработанный нами под руководством профессора А. П. Чуприкова, направлен на коррекцию психологических особенностей и сенсорики детей с аутизмом и отклонениями в развитии психики и поведения. С помощью этого метода появляется возможность влиять на онтогенез психики на самом раннем этапе, когда ребенок еще не может вступать в речевой контакт. Комплексность метода состоит в привлечении самых разных приемов воздействия на органы чувств и костно-мышечную систему (пальцевой массаж, элементы кранио-сакральной терапии, элементы йоги, динамическая 
гимнастика на мяче для фитнеса, сенсорные игры). Важным компонентом игровой кинезитерапии являются занятия на мяче.

Для родителей это также является хорошей терапией, т.к. они с удовольствием наблюдают за занятием, учатся новым приемам в игре с ребенком, благодаря чему ребенок становится более радостным, раскрывается в большем объеме.

Выводы и перспективы дальнейших исследований. Метод игровой кинезитерапии с использованием мяча для фитнеса можно рекомендовать для формирования психомоторной и интеллектуальной деятельности ребенка и становления у него важнейших двигательных навыков, составляющих основу не только игровой, но также учебной и трудовой деятельности. Этот универсальный метод оздоровления ребенка с аутизмом может применяться как самостоятельно, так и в сочетании с другими медицинскими и психологопедагогическими методами коррекции.

\section{Annotation}

Chorna T. V., PhD in the field of psychology, professor of ISA, head of the regional branch of the European Academy of Natural Sciences, psychologist of the inclusive resource center №3 Desnyansky district of Kyiv; Kyiv, Ukraine. Formation of Motor Skills in Children with Autism with the Help of Complex Game Kinesitherapy.

Key words: children, motor skills, kinesitherapy, autism, sensory integration.

Formulation of the problem. According to statistics, the number of children with autism is increasing every year worldwide, with a third of autistic children having movement disorders. Motor problems are as common as cognitive impairment. Therefore, exercise is necessary in a comprehensive training program for a child with autism. Physical education can be a support and guide in society for many children, a 
catalyst in the correct construction of the correctional and developmental process for a child with autism.

Analysis of recent research and publications. Children with autism have become an integral part of modern society. The incidence of autism in Kyiv has increased 4.5 times over the past eight years. Despite the large number of studies and publications, the problem of early childhood autism is relevant in the field of practical medicine, psychology, correctional pedagogy.

Children with autism not only differ in their behavior, thinking, perception of the world. They also often have movement disorders such as clumsiness, abnormal gait, coordination, hypotonia or muscle hypertonia. In children, motor disorders limit opportunities for development and knowledge of the world. This leads to isolation, limits social interaction. Therefore, physical education can be a support and guide in society for many children, a catalyst in the proper construction of the correctional and developmental process for a child with autism.

Formulating the purpose of the article. The purpose of the study is to study the motor characteristics of children with autism and to develop an author's effective method of forming motor skills in them.

The presentation of the main material. The method of complex game kinesitherapy, developed by us under the guidance of Professor A. P. Chuprikov, is aimed at correcting the psychological characteristics and sensory characteristics of children with autism and disorders in the development of psyche and behavior. With this method, it is possible to influence the ontogenesis of the psyche at the earliest stage, when the child can not yet enter into verbal contact. The complexity of the method is to involve various methods of influencing the senses and musculoskeletal system (finger massage, elements of craniosacral therapy, elements of yoga, dynamic gymnastics on fitness balls, sensory games). An important component of game kinesitherapy is ball training. 
For parents, this is also a good therapy, because they are happy to watch the lesson, learn new techniques in playing with the child, so that the child becomes happier, reveals more.

Conclusions and prospects for further research. The method of game kinesitherapy with the use of a fitness ball can be recommended for the formation of psychomotor and intellectual activity of the child and the formation of the most important motor skills that form the basis of not only play, but also learning and work. This universal method of rehabilitation of a child with autism can be used alone or in combination with other medical and psychological and pedagogical methods of correction.

Ключевые слова: дети, двигательные навыки, кинезитерапия, аутизм, сенсорная интеграция.

Постановка проблемы. Согласно статистическим данным, количество детей с аутизмом с каждым годом увеличивается во всем мире. Часто первыми ставят диагноз родители, основываясь на собственных наблюдениях. Поскольку аутизм сопровождается особенностями поведения, родители ищут пути эффективной помощи своим детям. По мнению специалистов, у трети аутичных детей есть двигательные нарушения. Двигательные проблемы встречаются так же часто, как и когнитивные нарушения. Отмечается, что физические нагрузки необходимы в комплексной программе занятий для ребенка с аутизмом. Физкультура может стать поддержкой и проводником в социум для многих детей, катализатором в правильном построении коррекционно-развивающего процесса для ребенка с аутизмом. В целом, систематическое использование физических упражнений является важным фактором помощи детям с аутизмом. 
Анализ последних исследований и публикаций. Сегодня дети с аутизмом стали неотъемлемой частью современного общества. Заболеваемость аутизмом в Киеве за последние восемь лет выросла в 4,5 раза [1]. Несмотря на большое количество исследований и публикаций, проблема раннего детского аутизма является актуальной в области практической медицины, психологии, коррекционной педагогики.

Аутизм влияет на каждого человека по-разному, поэтому и симптомы имеет разные. Коварство аутизма в том, что заметить его при обычном краткосрочном осмотре даже очень опытному врачу первичного звена не всегда легко. Эти проявления не столь категоричны и не так бросаются в глаза, как, например, повышенная температура, кашель или сыпь. Поэтому огромная надежда в деле первичной диагностики аутизма именно на родителей и семью [2].

Наиболее ярко картина нарушения проявляется от двух с половиной до трех лет. До этого возраста симптомы выражены слабо. Часто педиатры, детские психиатры не могут увидеть в ранних симптомах аномалии развития. Советуют родителям немного подождать, надеясь, что ребенок перерастет необычные проявления. Иногда родители отказываются замечать ранние патологии или не могут заметить, если это первый ребенок. Чтобы установить диагноз, консультации у педиатра недостаточно. Медицинских анализов, с помощью которых можно диагностировать аутизм, не существует. Диагноз ставится на основании наблюдения за тем, как ребенок ведет себя и общается.

Именно поэтому симптомы аутизма первыми замечают те люди, которые смотрят за ребенком. Поскольку аутизм проявляется в поведении, речи и общении, родители замечают, что ребенок ведет себя не так, как другие дети его возраста, играет в одиночестве, не смотрит в глаза другим. Примерно половина родителей замечают необычное поведение ребенка к полутора годам, к двум 
годам на отклонения обращают внимание $80 \%$ родителей. Часто у родителей создается ощущение, что ребенок живет в своем отдельном мире. Проявляются повторяющиеся ритуалы поведения, интересы и игры. Например, ребенок все время раскачивается, ненормально привязан к определенным предметам или сильно расстраивается, если меняется привычный ход вещей. Стереотипное поведение для многих людей с аутизмом носит компенсирующий характер, регулирующий их сенсорную систему и помогающий им справиться с сенсорной перегрузкой.

Когда ребенку диагностируют аутизм, педагогический приоритет ставится на изменение особенностей поведения для развития социальных и коммуникативных навыков, в то время как «сенсорные нужды» ребенка игнорируются [3, стр. 155]. По мнению профессора О. Богдашиной из Лондона, для детей с аутизмом, помещенных в сенсорно-коммуникационную терапию, ситуация складывается лучше, чем если бы их поместили в классы, где основной упор делается на выработку социальных, коммуникативных навыков.

Дети с аутизмом не только отличаются своим поведением, мышлением, восприятием мира. У них еще часто встречаются двигательные нарушения в виде неуклюжести, необычной походки, координации движения, гипотонус или гипертонус мышц. Еще в первых описаниях аутизма шла речь о том, что 50-80\% людей с аутизмом испытывают двигательные нарушения.

Новые данные указывают на то, что у всех без исключения детей с расстройствами аутистического спектра наблюдаются двигательные нарушения, которые проявляются в разной степени. У детей двигательные расстройства ограничивают возможности для развития и познания мира. Это приводит к замкнутости, ограничивает социальное взаимодействие.

Профессор Эндрю Уайтхаус из института Телетон Кидз, Австралия, и его коллеги в ходе исследований диагностической оценки детей с аутизмом в 
возрасте от 6 лет и младше обнаружили, что у трети аутичных людей есть двигательные нарушения, на которые редко обращают внимание [4].

Несомненно, это является проблемой, но выход заключается в создании благоприятных условий для систематических и правильно организованных занятий физическими упражнениями. В семьях, где есть дети с аутизмом, родители прибегают к различным видам помощи своим детям. При интенсивном вмешательстве, дети с аутизмом очень загружены коррекционными занятиями. Именно поэтому физические упражнения оказываются последними в списке задач, и часто до них не доходит очередь. По мнению некоторых родителей, вещи, за которые идёт борьба при аутизме, важнее физкультуры.

Однако, специалисты из разных стран считают, что физические нагрузки необходимы в комплексной программе занятий для ребенка с аутизмом. Физкультура может стать поддержкой и проводником в социум для многих детей, катализатором в правильном построении коррекционно-развивающего процесса для ребенка с аутизмом.

Во многих странах для работы с детьми-аутистами осторожно используют групповой метод, напоминающий ЛФК. К нему прибегают в работе с детьми старше 4 лет и подростками. По мнению некоторых специалистов (DevidGeslak, сертифицированный фитнес-консультант Американского колледжа спортивной медицины, автор и координатор программ физической терапии для детей с аутизмом в штате Иллинойс; Пол Кожокару, Румыния, автор 3С терапии и др.), ребенок должен самостоятельно изъявить желание включиться в процесс обучения. М. Кришталь-Слепян (Израиль) утверждает, что спорт не вытесняет обучение другим навыкам, а является их катализатором, помогает правильно построить коррекционно-развивающий процесс для ребенка с аутизмом [5]. 
Многие дети с аутизмом страдают дефицитом внимания. Доктор Гимпель, израильский специалист по СДВГ, детский психиатр и невролог, часто рекомендует детям перед напряженной умственной деятельностью позаниматься спортом. Он советует такие виды спорта, как бег или прыжки. По мнению доктора Гимпеля, концентрация внимания значительно улучшается после такого вида деятельности.

Формулирование цели статьи. Цель исследования - изучить двигательные особенности детей с аутизмом и разработать авторский эффективный метод формирования двигательных навыков у детей с аутизмом.

Гипотеза исследования основывается на том, что на расстройства сенсорного синтеза при детском аутизме раньше не обращали внимания ни врачи, ни медицинские психологи, хотя сенсорный синтез является базовой чертой человеческой психики. Именно с расстройствами сенсорного синтеза связано много особенностей патопсихологических черт детского аутизма. Наши исследования призваны доказать, что существуют методы вмешательства (нефармакологические), которые могут помочь ребенку с аутизмом улучшить психическое состояние за счет налаживания в нее сенсорного синтеза.

Объект исследования: психофизические особенности детей с аутизмом.

Предмет исследования: влияние комплексной игровой кинезитерапии на формирование двигательных навыков у детей с аутизмом.

Изложение основного материала. В последнее время широкое распространение получил метод комплексной игровой кинезитерапии, разработанный нами под руководством профессора А. П. Чуприкова. Метод направлен на коррекцию психологических особенностей и сенсорики детей с аутизмом и отклонениями в развитии психики и поведения. С помощью этого метода появляется возможность влиять на онтогенез психики на самом раннем этапе, когда ребенок еще мал и не может вступать в речевой контакт, т.е. когда 
его психическая деятельность ограничивается чувствованием и примитивными ответными реакциями, а само чувствование нарушено, повергнуто в состояние сенсорной дезинтеграции. Именно раннее вмешательство помогает ребенку быстрее и качественнее преодолеть проблемы своего развития.

Особенностью авторского метода кинезитерапии является игровая форма [6; 7]. Игра способствует созданию близких отношений между участниками, снимает напряженность, тревогу, страх перед окружающими, повышает самооценку, позволяет проверить себя в различных ситуациях общения. Комплексность метода состоит в привлечении самых разных приемов воздействия на органы чувств и костно-мышечную систему (пальцевой массаж, элементы кранио-сакральной терапии, элементы йоги, динамическая гимнастика на мяче для фитнеса, сенсорные игры) [8].

Важным компонентом игровой кинезитерапии являются занятия на мяче. Начиная с самого раннего детства и буквально до конца жизни, этот необычный по своим качествам предмет становится самым любимым «физкультурным снарядом», помогающим разностороннему развитию каждого, кто бы с ним ни соприкасался.

Используется гладкий мяч диаметром 75-85см. Мяч должен быть изготовлен из качественного материала, который не вызывает аллергии, не имеет неприятного запаха. Мяч является прекрасным тренажером для тренировки вестибулярного аппарата, расслабления мышечных групп, снятия напряжения, укрепления мускулатуры позвоночника, улучшения подвижности суставов. Но не всегда ребенок бывает сразу готов к занятиям на мяче. Иногда дети испытывают страх при появлении в доме большого мяча. В таких случаях можно прибегнуть к некоторым хитростям. К примеру, показать малышу упражнения на мяче с его любимым медвежонком (своего рода анонс будущего занятия). Или сесть на мяч вместе с ребенком и немного попрыгать. Если 
ребенок вам не доверяет, то здесь могут прийти на помощь родители и вместо вас выполнять с ребенком необходимые упражнения под вашим руководством. На мяче выполняются покачивания в разные стороны, кружения, прогибания, переворачивания ребенка со спинки на животик и наоборот. Мяч можно использовать в качестве батута. Мяч сам по себе - очень подвижный инструмент, поэтому необходимо соблюдать осторожность во избежание травм. При помощи мяча легко можно менять положение тела относительно горизонта, подбрасывать малыша вверх, съезжать с мяча вниз на пол, играть с ним в футбол, выполнять броски через голову, ударять руками о мяч. Игры на мяче проходят очень динамично, весело. Даже самый замкнутый ребенок не может устоять перед таким «другом». При помощи мяча можно вызвать у ребенка новые эмоции, которые он никогда раньше не испытывал в повседневной жизни. Не всегда это радость и восторг. Иногда это может быть возмущение и даже негодование, т.к. нарушили его привычный образ жизни. Мяч является неким провокатором, который подталкивает ребенка по-новому проявлять свои эмоции, которые, в свою очередь, также являются для него новыми. В таких ситуациях часто можно наблюдать, как у детей, которые не разговаривают, появляются новые звуки, а у некоторых даже появлялись первые слова (например, «помогите, спасите»). При помощи мяча меняется отношении ребенка к окружающему миру. Во многих семьях дети малоподвижны. Даже активный ребенок испытывает недостаток в движении. Для родителей это также является хорошей терапией, т.к. они с удовольствием наблюдают за занятием, учатся новым приемам в игре с ребенком, часто с удовольствием присоединяются к уроку. От этого ребенок становится более радостным, ему хочется продемонстрировать свои новые возможности, он раскрывается в большем объеме [9, стр. 162, 163]. 
Идеальная шаровидная геометрическая форма мяча придает ему особые аэродинамические свойства. С одной стороны, они облегчают преодоление сопротивления воздушной среды и увеличивают скорость его полета, а с другой, ограничивают время и площадь контакта, что затрудняет управление им. Это предъявляет исключительно высокие требования к ловкости и координации движений и помогает их совершенствованию. Поэтому мяч следует рассматривать как предложенный самой природой наиболее эффективный способ развития координационных способностей ребенка $[10$, стр. $18]$.

Выводы и перспективы дальнейших исследований. Имеются все основания для того, чтобы метод игровой кинезитерапии с использованием мяча для фитнеса отнести к числу самых полезных для формирования психомоторной и интеллектуальной деятельности ребенка и становления у него важнейших двигательных навыков, составляющих основу не только игровой, но также учебной и трудовой деятельности. Этот универсальный метод оздоровления ребенка с аутизмом может применяться как самостоятельно, так и в сочетании с другими медицинскими и психолого-педагогическими методами коррекции

\section{Список використаних джерел}

1. Статистика захворюваності на аутизм [Електронний ресурс].- режим доступу: https://www.rbc.ua/rus/news/kieve-zabolevaemost-autizmom-vyrosla-4-51522684769.html

2. Гінзбургг В. Величезна надія в справі діагностики аутизму покладається на батьків / Валентина Гінзбург // Київ - офіційний портал https://kyivcity.gov.ua/news/velichezna_nadiya_u_spravi_pervinno_diagnostiki_autiz mu_pokladayetsya_na_batkiv_valentina_ginzburg/ 
3. Богдашина О. Б. Сенсорно-перцептивні проблеми при аутизмі / О. Б. Богдашина [ред. Череньова Є.А.].- Красноярськ, 2014.- 180 с.

4. Zeliadt N. Motor problems in autistic people may be grossly underestimated | Nicolette Zeliadt // Spectrum \{Електронний ресурс].- режим доступу: https://www.spectrumnews.org/news/motor-problems-in-autistic-people-may-begrossly-underestimated

5. Кришталь-Слепян М. Ода фізкультурі, або Чому спорт є необхідним в комплексній програмі занять для дитини з аутизмом / М. Криштваль-Слепян // Аутизмі порушення розвитку, 2018.- Т. 16.- № 1.- С. 61-68.

6. Чуприков А. П. Патент на корисну модель № 78372 «Спосіб лікування дитячого аутизму з застосуванням ігрової кінезітерапії»/ Чуприков А. П., Зайцев Д. В., Таршинов I. В., Чорна Т. В. // Зареєстровано в Державному реєстрі патентів України на корисні моделі 11.03.2013 р.

7. Чуприков А. П. Патент на корисну модель №88247 «Спосіб лікування дитячого аутизму». / Чуприков А. П., Чуприкова О. Г., Чорна Т. В., Таршинов I. В., Рожков В. С., Мишиєв В. Д., Зайцев Д. В., Чухраєв М. В. // Зареєстровано в Державному реєстрі патентів України на корисні моделі 11.03.2014 p.

8. Чуприков А. П. Про необхідність комплекмної сенсорної інтеграції в дітей $з$ патологією розвитку / А. П. Чуприков, Т. В. Чорна // Науковопрактичний Рецензуємий журнал «Вчені записки». Вісник Академії.- Хайфа, 2018.- T. 10.- №2. - C. 190-193.

9. Чорна Т. В. Порушення сенсорно-перцептивної сфери та методи іiі інтеграції в дітей з аутизмом / Т. В. Чорна // Колективна монографія «Цунамі дитячого аутизму» [ред. А. П. Чуприков].- М.: ІДГТ «Гнозис», 2017.- С. 154169.

10. Овчинников В. П. Баскетбол і здоров'я дитини / В. П. Овчинников, С. Л, Фетисова, А. А. Несмеянов.- Грозний, 2020.- 265с. 


\section{References}

1. "Statystyka zakhvoryuvanosti na autyzm" [Statistics on the incidence of autism] [Online], available at: https://www.rbc.ua/rus/news/kieve-zabolevaemost-autizmomvyrosla-4-5-1522684769.html, Uk.

2. Ginzburg, V. "Velychezna nadiya v spravi diahnostyky autyzmu pokladayet'sya na bat'kiv" [Great hope in the diagnosis of autism rests on parents], [Online], available at: https://kyivcity.gov.ua/news/velichezna_nadiya_u_spravi_ pervinno_ diagnostiki_autizmu_pokladayetsya_na_batkivburg_valent, Uk.

3. Bogdashina, O. B. (2014), "Sensorno-pertseptyvni problemy pry autyzmi" [Sensory-perceptual problems in autism], Krasnoyarsk, Ru.

4. Zeliadt, N. "Motor problems in autistic people may be grossly underestimated",| Spectrum, [Online], available at: https://www.spectrumnews.org/ news/motor-problems-in-autistic-people-may-be-grossly-underestimated, En.

5. Kryshtal-Slepyan , M. (2018), "Ode to physical education, or Why sport is necessary in a comprehensive program for children with autism", Autism developmental disorders, vol. 16 (1), pp. 61 -68, En.

6. Chuprikov, A. P. Zaitsev, D. V. Tarshinov, I. V. Chorna, T. V. (2013), “Patent na korysnu model' № 78372 "Sposib likuvannya dytyachoho autyzmu $z$ zastosuvannyam ihrovoyi kineziterapiyi”, [Patent for a utility model № 78372 "A method of treating childhood autism with the use of game kinesitherapy"], Registered in the State Register of Patents of Utility Models of Ukraine on March 11, 2013, Uk.

7. Chuprikov, A. P. Chuprikova, O. G. Chorna, T. V. Tarshinov, I. V. Rozhkov, V. S. Mishiev, V. D. Zaitsev, D. V. Chukhrayev, M. V. (2014), "Patent na korysnu model' №88247 “Sposib likuvannya dytyachoho autyzmu” [Patent for a utility model №88247 "Method of treating childhood autism"], Registered in the State Register of Patents of Utility Models of Ukraine on March 11, 2014, Uk. 
8. Chuprikov, A. P. Chorna, T. V. (2018), "On the need for comprehensive sensory integration in children with developmental pathology", Scientific and practical Peer-reviewed journal "Scientific Notes". Bulletin of the Academy, Haifa, vol. 10 (2), pp. 190-193, En.

9. Chorna, T. V. (2017), "Violation of the sensory-perceptual sphere and methods of its integration in children with autism", Kolektyvna monohrafiya "Tsunami dytyachoho autyzmu» [ed. A.P. Chuprikov], "Gnosis", Moscow, pp. 154-169, Uk.

10. Ovchinnikov, V. P. Fetisova, S. L. Nesmeyanov, A. A. (2020), "Basketbol $i$ zdorov"ye rebionka" [Basketball and child health], Grozny, Ru. 